\title{
PAPPASENG SEBAGAI KARAKTER MASYARAKAT BUGIS SULAWESI SELATAN
}

\author{
Jumrana \\ Program Studi Bahasa dan Sastra Indonesia, Fakultas Sastra \\ Universitas Muslim Indonesia \\ Jumrana095@gmail.com
}

\begin{abstract}
Abstrak
Salah satu peninggalan sejarah yang menyimpan berbagai aspek kebudayaan suku bangsa yang memiliki aksara sendiri ialah naskah. Orang Bugis adalah salah satu suku bangsa yang beruntung memiliki aksara sehingga aspek kebudayaan pada masa lampau masih dapat tersimpan dalam naskah Lontara. Salah satu bentuk naskah Lontara Bugis yang berhubungan dengan kearifan dikenal dengan istilah Pappaseng 'Pesan-pesan'; nasihat; wasiat'. Pappaseng sebagai salah satu bentuk pernyataan yang mengandung nilai etis dan moral, baik sebagai sistem sosial, maupun sebagai sistem budaya dalam kelompok masyarakat Bugis. Dalam pappaseng terkandung ide yang besarbuah pikiran yang luhur, pengalaman jiwa yang berharga, dan pertimbangan-pertimbangan yang luhur tentang sifat-sifat yang baik dan buruk. Pappaseng berasal dari kata paseng yang dapat berarti pesan(an) yang berisi nasihat bahkan merupakan wasiat yang harus diketahui dan dikenal.. Pappaseng pula dapat berisikan petunjuk-petunjuk dan nasihat dari nenek moyang orang Bugis pada zaman dahulu untuk anak cucunya agar menjalani hidup dengan baik. Fungsi pappaseng adalah sebagai sarana nasihat dan kritik, nasihat dan sumber nilai, pengawas dan pemelihara norma-norma dan hiburan. Pappaseng selain sebagai sarana pembentukan karakter juga menjadi sarana hiburan masyarakat Bugis.
\end{abstract}

Kata Kunci: Pappaseng, karakter, masyarakat Bugis

\section{PENDAHULUAN}

Kata "kebudayaan" berasal dari kata Sansekerta buddhayah yaitu bentuk jamak dari buddhi yang berarti "budi" atau "akal". Dengan demikian kebudayaan dapat diartikan "hal-hal yang bersangkutan dengan akal", (Koentjaraningrat 2015:146). Suku Bugis (To Ugi) adalah salah satu suku yang ada di Sulawesi Selatan. Namun, dalam perkembangannya, saat ini komunitas Bugis telah menyebar luas ke seluruh Nusantara. Ugi bukanlah sebuah kata yang memiliki makna. Tapi merupakan kependekan dari La Satumpugi, nama seorang raja yang pada masanya menguasai sebagian besar wilayah Provinsi Sulawesi Selatan. Budaya Bugis sesungguhnya diterapkan dalam kehidupan sehari-hari mengajarkan hal-hal yang berhubungan dengan akhlak sesama, seperti mengucapkan tabe (permisi) sambil berbungkuk setengah badan bila lewat di depan sekumpulan orang-orang tua yang sedang bercerita.

Paseng dapat diartikan sebagai perintah; nasihat; permintaan, amanat yang disampaikan lewat orang lain, perkataan; nasihat; wasiat yang terakhir. Pappaseng berasal dari kata dasar paseng yang berarti pesan yang harus dipegang sebagai amanat, berisi nasihat, dan merupakan wasiat yang perlu diketahui dan diindahkan.

Pappaseng dalam bahasa Bugis mempunyai makna yang sama dengan wasiat dalam bahasa Indonesia. Pappaseng 
dapat pula diartikan pangaja' yang bermakna nasihat yang berisi ajakan moral yang patut dituruti. pappaseng adalah wasiat orang tua kepada anak cucunya (orang banyak) yang harus selalu diingat sehingga amanatnya perlu dipatuhi dan dilaksanakan atas rasa tanggung jawab.

Jadi dapat diartikan pappaseng adalah pesan yang disampaikan secara lisan oleh orang-orang bijak dalam masyarakat Bugis terhadap raja yang berkuasa atau orang tua terhadap anakanaknya yang bertujuan membentuk karakter yang baik.

Orang Bugis adalah salah satu suku bangsa yang beruntung memiliki aksara sehingga aspek kebudayaan pada masa lampau masih dapat tersimpan dalam naskah Lontarak. Salah satu bentuk naskah Lontarak Bugis yang berhubungan dengan kearifan dikenal dengan istilah Pappaseng 'Pesan-pesan; nasihat; wasiat'

Pappaseng sebagai salah satu bentuk pernyataan yang mengandung nilai etis dan moral, baik sebagai sistem sosial, maupun sebagai sistem budaya dalam kelompok masyarakat Bugis. Dalam pappaseng terkandung ide yang besarbuah pikiran yang luhur, pengalaman jiwa yang berharga, dan pertimbangan-pertimbangan yang luhur tentang sifat-sifat yang baik dan buruk.

Kalangan masyarakat Bugis, pappaseng yang sangat dikenal antara lain: Pappaseng yang berasal dari Tomaccaé ri Luwu, Kajao Laliddong ri Boné, dan Arung Bilari Soppéng. Ketiga tokoh tersebut dikenal sebagai orang arif dan bijaksana, pada umumnya ditemukan dalam Lontarak attoriolong di berbagai daerah Sulawesi Selatan.

Pappaseng sarat dengan makna dan pesan-pesan moral, karena di dalamnya terkandung nilai-nilai luhur yang dapat dijadikan pedoman hidup, sebagai pengatur tingkah laku pergaulan dalam masyarakat. Karena itu, perlu adanya upaya pengkajian secara serius guna mengungkap kembali nilai-nilai luhur yang terkandung di dalamnya terutama nilai edukatif yang sangat diperlukan untuk pembinaan generasi sekarang dan generasi yang akan datang.

\section{PEMBAHASAN}

\section{Konsep Pappaseng}

Pappaseng sebagai falsafah hidup masyarakat Bugis di Sulawesi Selatan merupakan suatu bentuk ungkapan yang mencerminkan nilai budaya yang bermanfaat bagi kehidupan. Di dalam sebuah pappaseng terkandung suatu ide yang besar, buah pikiran yang luhur, pengalaman jiwa yang berharga, dan pertimbangan-pertimbangan yang luhur tentang sifat-sifat yang baik dan buruk. Nilai-nilai luhur dalam sebuah pappaseng dikemas dengan baik dalam sebuah konsep dengan makna yang bersifat abstrak sehingga untuk memahami makna itu memerlukan pendekatan-pendekatan tertentu, karena tidak menutup kemungkinan pula bahwa makna di balik pappaseng itu bersifat situasional.

Pappaseng memiliki berbagai fungsi yaitu:

\section{a. Sebagai Sarana Dan Kritik Sosial}

Kerifan lokal Bugis banyak terdapat dalam pappaseng yang memuat beberapa nilai luhur yang berfungsi untuk sasaran kritik atau sindiran penyelewengan atau kesewenang-wenangan yang dilakukan oleh pemerintah raja, orang kaya, orang miskin, ulama, dan penegak hukum. 
b. Sebagai Nasihat dan Sumber Nilai

Nasihat atau kritik pada zaman dahulu dilakukan oleh masyarakat Bugis dengan bahasa santun. Hal ini ditandai dengan bahasa santun yang memilikii ciri pengguna bentuk-bentuk kiasa. Jika seseorang dari masyarakat Bugis tidak menggunakan perumpamaan dalam pilihan kata, terutama untuk mengkritik maka seseorang dianggap tidak beretika dan tidak santun.

c. Sebagai Pengawas dan Pemelihara Norma-norma

Kearifan lokal Bugis memuat beberapa nilai luhur yang berfungsi sebagai sarana pengawas dan pemeliharaan norma-norma kehidupan dalam masyarakat Bugis. Eksistensi norma dan hukum dalam pappaseng adalah aturan yang telah disepakati bersama oleh suatu masyarakat dan tidak dapat diubah kecuali kesepatakan bersama kembali.

\section{Pappaseng sebagai Falsafah Hidup Masyarakat Bugis}

Pappaseng seperti halnya dengan setiap kearifan atau kebijakan, sedikit atau banyak selalu mengalami pergeseran nilai sepanjang sejarah yang dilaluinya. Namun, di balik itu niscaya akan tetap juga ada yang tidak berubah nilainya dan tidak bertentangan dengan falsafah negara sebagai nilai nasional yang dianut bersama. Karena itu, dianggap perlu untuk mengkaji dan menampilkan kembali naskah-naskah daerah khususnya yang ada dalam bentuk pappaseng. Dengan demikian, maka nilainilai budaya daerah khususnya budaya masyarakat Bugis dapat dipertahankan terutama nilai-nilai budaya yang dianggap masih relevan dengan keadaan dan pertumbuhan masyarakat sekarang ini maupun masyarakat pada generasi yang akan datang.

Pappaseng merupakan suatu bentuk pernyataan dengan bahasa yang mengandung nilai etis dan moral, baik sebagai suatu sistem sosial maupun sebagai sistem budaya dari suatu kelompok masyarakat Bugis.

Filsafat dapat pula diartikan sebagai suatu kebijaksanaan hidup, usaha kebatinan, angan-angan, sikap, metode, dan teknik (Ali, dkk., 1997). Dengan demikian falsafah hidup dapat diartikan sebagai suatu pengajaran atau pedoman yang sarat dengan berbagai macam kebijaksanaan yang penuh kearifan dalam mengatur berbagai aspek kehidupan masyarakat Bugis.

\section{Corak Masyarakat Bugis}

Budaya Bugis sesungguhnya yang diterapkan dalam kehidupan sehari-hari mengajarkan hal-hal yang berhubungan dengan akhlak sesama, seperti mengucapkan tabe' (permisi) sambil berbungkuk setengah badan bila lewat di depan sekumpulan orang-orang tua yang sedang bercerita. Suku Bugis juga kental dengan adat yang khas: adat pernikahan, adat bertamu, adat bangun rumah, adat bertani, prinsip hidup, dan sebagainya. Meskipun sedikit banyaknya telah tercampur dengan ajaran Islam. Adat sendiri yang dimiliki Suku Bugis menandakan satu hal: Suku Bugis pada masanya memiliki peradaban yang luar biasa.

Umumnya rumah orang Bugis berbentuk rumah panggung dari kayu berbentuk segi empat panjang dengan tiang-tiang yang tinggi memikul lantai dan atap. Konstruksi rumah dibuat secara lepas-pasang (knock down) sehingga bisa 
dipindahkan dari satu tempat ke tempat lain. Orang Bugis memandang rumah tidak hanya sekedar tempat tinggal tetapi juga sebagai ruang pusat siklus kehidupan. Tempat manusia dilahirkan, dibesarkan, kawin, dan meninggal. Karena itu, membangun rumah haruslah didasarkan tradisi dan kepercayaan yang diwarisi secara turun temurun dari leluhur. Konstruksi berbentuk panggung yang terdiri atas tingkat atas, tengah, dan bawah diuraikan yaitu: Tingkat atas digunakan untuk menyimpan padi dan benda-benda pusaka. Tingkat tengah, yang digunakan sebagai tempat tinggal, terbagi atas ruangruang untuk menerima tamu, tidur, makan dan dapur. Tingkat dasar yang berada di lantai bawah diggunakan untuk menyimpan alat-alat pertanian, dan kandang ternak.

\section{Pappaseng Membentuk Karakter}

Pendidikan karakter telah menjadi perhatian di berbagai masyarakat. Karakter dalam masyarakat mempunyai perang penting untuk mempersiapkan generasi yang berkualitas. Pendidikan karakter pun menjadi perhatian dalam dunia pendidikan karena munculnya berbagai masalah yang ditimbulkan oleh generasi muda akibat gagalnya pembentukan karakter dalam keluarga dan lingkungan masyarakat.

Dalam konteks pembelajaran di sekolah, menurut Mansyur (2016) muatan pendidikan karakter dimanifestasikan dalam pembelajaran menggunakan bahan ajar. Bahan ajar untuk peserta didik membutuhkan materi pembelajaran yang dapat mengajarkan nilai-nilai perkembangan kepribadian peserta didik. Nilainilai perkembangan dalam pembelajaran tersebut terkumpul dalam suatu wadah yang disebut pendidikan karakter.
Pendidikan karakter dapat tercapai pada pendidikan anak apabila peran orang tua meluangkan waktu untuk perhatian kepada anak dimaksimalkan. Pendidikan karakter tidak dapat dipisahkan dengan pengajaran sastra karena karya sastra mempunyai nilai-nilai pendidikan akhlak didalamnya, contoh cerita rakyat "Bawang Merah dan Bawang Putih" mengandung nilai pendidikan kemanusiaan atau karakter yang baik meskipun di dalamnya terdapat pula karakter yang jahat tetapi kita harus mengambil sisi positif dalam cerita tersebut. Karakter baik dan jahat dalam dunia sastra dihadirkan secara bersamaan sehingga menimbulkan konflik-konflik agar pembaca/penonton makin penasaran dengan alur cerita sehingga mengikutinya sampai akhir cerita.

Beberapa contoh pappaseng dan nilai-nilai utama yang terkandung di dalamnya, dan dijadikan sebagai tatanan hidup masyarakat akan dikemukakan sebagai berikut:

a. Nilai-nilai yang Berkaitan dengan Deceng Na Jak

Baik dan buruk adalah nilai sebuah perbuatan yang menjadi ukuran dari hasil perbuatan, atau sebuah pedoman perbuatan yang bisa dilakukan atau tidak bisa dilakukan. Nilai dilembagakan dalam kearifan orang-orang tua terdahulu yang dilestarikan dalam bentuk paseng. Paseng dapat digolongkan sebagai karya sastra seperti halnya pantun, peribahasa dan elong.

Paseng bertujuan mengajarkan tentang hal-hal baik dan buruk kepada generasi muda dalam masyarakat Bugis, deceng na jak merupakan pesn berbentuk lisan yang biasanya diucapkan kepada anak-anak untuk mereka berbuat baik. 
Karakter deceng dibagi menjadi beberapa bagian yaitu: deceng kiniwwa (baik angan-angan/ hati), madeceng tuona (baik kehidupannya), madeceng linona (orang sukses di dunia), madeceng akherakna (agamawan, ustazd. Kiyai), madeceng gauk (orang yang sopan, berbudi pekerti, baik tingkah laku), madeceng urukna (keturunan baik-baik), madeceng ampe (baik hati).

Pappaseng berikut mengungkapkan petunjuk untuk mengetahui tentang yang baik dan yang buruk. Kata 'deceng' artinya 'baik' dan 'majak' artinya 'jelek' atau 'buruk' yanf dipresentasikan dalam paseng Tomatoa berikut:

"rekkuwa engka kedo rinawanawammu tangngai addimunrinna, rekkawa naddimunri jak napoancajiwi

Dewata Seuwwae deceng narekko kedo maja ammatu-matuangngi apa temmapuji Dewata Seuwwa-e rija-e”.

Artinya: bila ada keinginan dalam hatimu, pandanglah akibatnya jika menimbulkan keburukan, semoga Allah mengubah menjadi sebuah kebaikan, sebaiknya jika terbelit sesuatu prasangka buruk, perlambatlah waktunya karena Allah yang Maha Tunggal tidak menyukai keburukan.

Pappaseng tersebut menggunakan kata 'jak' dan 'deceng'. Pesan yang mengingatkan orang agar berhati-hati dalam mengambil keputusan. Suatu keputusan untuk dipertimbangkan atas baik dan buruk berdasarkan oleh hati, jika sesuai dengan anjuran Allah maka perbuatan itu dapat dilakukan, jika tidak sesuai dengan hati maka perbuatan itu tidak boleh dilakukan.

b. Nilai-nilai yang Berkaitan dengan

Lempuk

Karakter jujur (lempuk), alampureng (kejujuran) terkait dengan sifat seseorang yang tulus hati, tidak curang, ikhlas dalam berinteraksi dengan sesame manusia. Karakter jujur sangat dijunjung tinggi oleh masyarakat Bugis seperti yang terungkap dalam beberapa data pappaseng tomatoa.

Karakter jujur dalam ideology Bugis merupakan karakter yang lahir dari penjabaran adak na gauk. Kejujuran merupakan landasan pokok dalam menjalin hubungan dengan sesama manusia dan merupakan salah satu faktor yang sangat mendasar di dalam kehidupan manusia. Karakter jujur dibagi dalam beberapa sikap yaitu, kejujuran terhadap diri sendiri, kejujuran diri terhadap Tuhan, kejujuran Tuhan terhadap hambanya, kejujuran diri terhadap sesame, kejujuran pemerintah terhadap rakyat dan kejujuran rakyat terhadap pemerintah. Dalam pappaseng diungkapkan sebagai berikut:

"Sininna gauk-e iyapa namadeceng narekko mattaratek-I; 1) issengngi majak-e mutetengngi mupenessaiwi decengnge mupogauk, 2) issengngi tencajie namupenessaiwi jajie, 3) issengngi temmakkuae namupenessaiwi makkuwae, 4) issengngi macekkoe namupenessaiwi malempuk-e".

Artinya: semua perbuatan akan baik apabila teratur; artinya (1) ketahuilah yang buruk, lalu kamu pegang dan pahami yang baik lalu kamu kerjakan, (2) ketahuilah yang mustahil dan pahami yang mungkin, (3) ketahuilah yang tidak semestinya dan pahamilah yang semestinya, (4) ketahuilah yang culas dan pahami yang jujur.

c. Nilai-nilai yang Berkaitan dengan

\section{Warani}

Warani 'berani' artinya sifat yang dimiliki oleh seseorang yang melakukan sesuatu perbuatan atau pekerjaan yang mengandung tantangan dan resiko. 
Beberapa tanda pemberani yaitu tidak takut mati, senang dengan tantangan, suka mengurusi orang banyak, tidak takut kehilangan, dan tidak takut terhadap musuh.

Orang yang berani diberi gelar dalam masyarakat Bugis sebagai towarani. Tosegge, towaranie. Gelar tersebut bermakna positif yaitu pemberani, orang yang berani dalam hal membela kebenaran, membela rakyat kecil, berani mengambil resiko untuk mempertahankan kebenaran.

Nilai-nilai yang berkaitan dengan keberanian digambarkan dalam pappaseng tomatoa yaitu sebagai berikut:

"Tanranna tau waranie; 1) napappada-pada I riengkanna enrengnge ridekna, 2) ceddekna enrengnge rimaegana, 3) ripaddiolona nenniya ripaddimunrinna,

rimengkalinganna kareba majak deknatassunrewa nakareba madeceng deknatakkauang".

Artinya: Tanda orang berani adalah (1) ada atau tidak ada sama saja baginya, (2) sedikit atau banyak sama saja baginya, (3) ia di depan atau di belakang tidak menjadi masalah baginya, (4) ia tidak gentar mendengar kabar buruk dan tidak menampakkan kegembiraan yang berlebihan bila mendengar kabar baik.

d. Nilai-nilai yang Berkaitan dengan Ada Na Gauk

Ada na gauk bermakna kata dan perbuatan. Kata yang bermakna 'ucapan' dan gauk bermakna 'perilaku' yaitu segala gerak gerik tingkah laku. Kata dan perbuatan sebagai pappaseng tumatoa dalam masyarakt Bugis bertujuan untuk pembentukan karakter baik. Kata dan perbuatan direpresentasikan dalam bahasa Bugis dengan istilah 'ada na gauk'. Gauk 'perbuatan' adalah representasi dari tindakan dalam merespon ada 'kata/pernyataan' seseorang dengan cara yang bermakna.

Tema dalam pappaseng tomatoa banyak ditemukan tentang tema yang menganjurkan pada anak-anaknya, sanak keluarga untuk berbuat sesuai kata dan perbuatan. Mengucapkan sesuatu yang dapat dibuktikan dalam karya nyata. Pappaseng tersebut bertujuan membiasakan anak-anak untuk selalu berkata apa yang dapat dilakukannya. Berikut adalah pappaseng yang menganjurkan berkata benar yaitu:

"Makkedatopi ti tioloe; narekko balio ada, issengngi gauk situruk-e adek-e, enrengnge sarak-e, kua-e rapangnge, maka mottongengi adanna tau-e naia mepatettongngi pabali ada. Apak iaritu natania balinna adanna tau-e mubaliangngi, naecawa-cawaino, napoisseng toni dekna tomacca ri wanuae".

Artinya: Orang-orang tua dahulu berpesan, jika kamu akan menjawab perkataan, ketahuilah hal yang sesuai dengan adat, syariat agama, misalnya hukum analogi yang dapat mengatasi perkataan lawan, itulah yang kamu jadikan landasan untuk menjawab perkataan orang. Apalagi engkau menjawab perkataan orang yang tidak sesuai dengan semestinya maka orang itu akan menertawaimu dan mengira sudah taka da lagi orang pintar di dalam negeri.

e. Nilai-nilai yang Berkaitan dengan Sipakatau

Sipakatau bermakna memanusiakan manusia, menghargai orang seperti menghargai diri sendiri. Sipakatau berasal dari kata 'tau' yang berarti orang. Pakatau 
bermakna 'menghargai orang lain'. Jadi sipakatau bermakna pemberani kepada seseorang karena mereka berhak mendapatkannya seperti penghargaan, kasih sayang, dan cinta.

Nilai-nilai ada na gauk terdapat nilai sipakatau yaitu bagian dari ideologi sirik na pesse yang sering diucapkan orang tua terhadap anak-anaknya untuk membentuk karakter baik. Sipakatau merupakan butir kedua dari sirik na pesse. Ideology sipakatau dimanifestasikan dalam karakter malebbi (santun), ati mapaccing (baik hati), dan malempuk (adil).

Sipakatau adalah salah satu ideologi kultural Bugis memuat tentang prinsip kemanusiaan yang dimiliki oleh orang Bugis, seperti berikut:

"Iapa nariaseng tau, seddie rupa tau narekko engka sirik na bolai apa ia tau dekgaga sirikna ebarakna padai olo-kolok-e.

$\begin{array}{ll}\text { Sirikna rakyake engkai } \\ \text { ripammarentae } & \\ \text { Arajanna pamarentae engkai } \\ \text { rirakyakna }\end{array}$

Sirikna tomatoae engkai ri anakna

Artinya: Seseorang dianggap manusia kalau memiliki rasa malu sebab orang yang tidak memiliki rasa malu bagaikan seekor binatang.

Harga diri rakyat ada pada pemerintah Kebesaran pemerintah ada pada rakyatnya Harga diri orang tua ada pada anaknya

f. Nilai-nilai yang Berkaitan dengan Asseddi-Seddingeng

Salah satu tema yang banyak diungkap dalam pappseng tomatoa adalah asseddiseddingeng (gotong royong); atau bekerja bakti. Asseddi-seddingeng adalah bentuk kerja sama dalam membangun masyarakat. Karakter gotong royong adalah sifat yang melekat pada diri masyarakat dalam bekerja bersama-sama saling tolong menolong, bantu-mambantu mengerjakan sesuatu.

Gotong royong merupakan karakter bangsa Indonesia yang telah diperkenalkan oleh Bung Karno sejak pembentukan ideolog negara dan sebagai karakter bangsa yang tidak boleh dihilangkan. Gotong royong sering diungkapkan 'Mabbulo sibatang' bersifat seperti bambu yang bermakna saling menopang untuk membangun keuatan. Prinsip mabbulo sibatang menghilangkan karakter negative yang tidak mau dikalah oleh orang lain atau tidak mau berada di bawah orang lain.

Asseddingeng adalah persatuan dalam melakukan pekerjaan untuk membangun dengan tidak mengharap imbalan/upah. Berikut pappaseng yang memuat tema assedding-seddingeng yaitu:

"Rebba sipatokkong, malik siparappe, sirui menrek tessirui no, malilu sipakaingek, maengekpi napaja"

Artinya: Rebah saling menegakkan, hanyut saling mendamparkan, tarik menarik ke atas bukan saling menarik ke bawah, khilaf saling memperingati.

Pappaseng di atas mengandung sifat gotong-royong atau tolong menolong sesam manusia. Adapun Pappaseng lain ialah:

\section{"Malik siparappeki \\ Rebba sipatokkokki}

Siri menre, tessirik nok"

Artinya: Kalau kita hanyut bersama, hendaknya saling menyelamatkan,

Kalau kita tumbang bersama hendaknya saling mengangkat,

Kalau kita mujur berprestasi menanjak, pantang untuk diturunkan.

Dengan demikian, seandainya dalam masyarakat Sulawesi Selatan ber-kembang 
masyarakat oposisi, yakni setiap orang yang akan naik ditarik kakinya ke bawah, berarti suatu penyimpangan terhadap isi pappaseng tersebut.

g. Nilai-nilai yang Berkaitan dengan

\section{Etos Kerja}

Dalam kaitannya dengan etos kerja, sejak dahulu orang Bugis dikenal sebagai pelaut ulung. Karena akrabnya dengan air dan laut, maka sifat-sifat dinamis dari gelombang yang selalu bergerak dan tidak mau tenang itulah yang mempengaruhi jiwa dan pikirannya (Said, 1997:4). Haltersebut dilukiskan sebagai sifat dinamis, penuh semangat tanpa kenal putus asa, dan pantang mundur yang dapat dilihat dalam pappaseng berikut ini:

"Pura babbara sompekku

Pura gucciri gulingku

Ulebbirenngi tellenngé natowalié"

Artinya: Layarku sudah berkembang

Kemudiku sudah terpasang

Kupilih tenggelam daripada

kembali"

Demikianlah sifat yang hebat, pantang mundur bila ingin mencapai sesuatu.

\section{PENUTUP}

Dalam pappaseng terdapat nilainilai luhur yang sarat dengan pesan-pesan moral, dan sampai saat ini masih dipegang teguh oleh masyarakat Bugis di Sulawesi Selatan. Namun, kehidupan masyarakat yang dinamis, mengalami perubahan seiring dengan perkembangan jaman. Dengan demikian, nilai-nilai tersebut senantiasa mengalami pergeseran pula.

\section{DAFTAR RUJUKAN}

Ali, Lukman dkk. (1997). Kamus Besar Bahasa Indonesia. Jakarta: Balai Pustaka.

Amin, K.F. (2015). Pappaseng Ugik. Makassar: Garis Khatulistiwa.

Koentjaraningrat. (2015). Pengantar Ilmu Antropologi. Jakarta: Rineka Cipta.

Mansyur, U. (2016). Pemanfaatan Nilai kejujuran dalam Cerpen sebagai Bahan Ajar Berbasis Pendidikan Karakter. In Mengais Karakter dalam Sastra: HISKI Makassar https://doi.org/10.17605/OSF.IO/Z4T $3 \mathrm{Y}$

Mansyur, U. (2018). Kiat dan Teknik Penulisan Skripsi bagi Mahasiswa. INA-Rxiv. https://doi.org/10.31227/osf.io/juds7

Pamiring Waweng. (2013). Ada Pappaseng.

(Online, http://bungawellu.blogspot.co.id/ 2013/04/ ada-pappaseng.html/)

Syamsudduha. (2013). Pappaseng Sebagai Falsafah Hidup Masyarakat Bugis di Sulawesi Selatan (Online, http://syamsudduhaa.blogspot.co.id/2 013/10/pappaseng-sebagai-falsafahhidup.html/)

Zulfaworld. (2014). Kebudayaan Suku Bugis.

(Online, https://zulfaworld.wordpress.com/ 2014/03/19/kebudayaan-suku-bugis/) 